\title{
Reforming medical education in the United Kingdom: lessons for Australia and New Zealand
}

\author{
Richard B Hays
}

T he United Kingdom provides a public health system spanning primary, secondary and tertiary care in both community and hospital settings, managed by one level of government, through the National Health Service (NHS). The NHS was established in 1948 "to provide healthcare for all citizens, based on need, not the ability to pay". "Although regarded as high quality service in international comparisons, ${ }^{1}$ the NHS, like other national health systems, is struggling to provide a service that meets all expectations. There are increasing expectations of higher quality of care, often more expensive and dependent on emerging technology, which often prolongs and complicates care. There are also difficulties in recruitment and retention of an appropriately skilled workforce, partly due to the European Working Time Directive (which limits weekly working hours), the imminent retirement of the "baby boomer" generation, and the impact of European Union immigration laws, which make more difficult the traditional reliance on international medical graduates from former Commonwealth countries.

Responses have come from both the community and the government. A private health care system has developed alongside and almost completely independent of the NHS, particularly in the south-east of England, to cater for those prepared to pay to avoid waiting lists for both simpler and more expensive elective procedures. Those who cannot afford private health care are increasingly challenging decisions that can be seen as "rationing" health care, and are increasingly winning. The government response has been broad and expensive, including increased infrastructure development, often through Private Finance Initiatives, substantial pay rises for doctors and nurses, and changes to health workforce career structures and training pathways, predominantly in the medical profession. Despite these responses, the NHS is regarded as being in chaos, with substantial budget overruns and failures to meet clinical performance targets. This has provoked consideration of more radical proposals, such as broadening the funding base through "opt-out" health insurance levies, and allowing further corporatisation of primary care. ${ }^{2,3}$ Further, the education and training initiatives have attracted controversy because of problems managing the single, nationally centralised selection and matching system. As a result of this perceived failure, potentially resulting in unemployment for recent UK medical graduates, managers have resigned, the system is being redesigned almost in panic mode, and there is a risk that some of the reforms may be cancelled.

Here, I describe the reforms to medical education in the UK, discuss why they have encountered so much difficulty, and suggest lessons for those considering similar reforms elsewhere.

\section{Rationale for reforming medical education}

Medical education has not always necessarily reflected the needs of society. Undergraduate medical education is largely a responsibility of universities, which are primarily concerned with academic standards, developing thinking and questioning, and encouraging research. The medical profession also has great influence, as the

\section{ABSTRACT}

- Medical education faces global challenges because of the changing health care needs of an ageing and more demanding society, and the consequent requirement for increased health care workforce capacity and different workforce models.

- In the United Kingdom, education reform has spanned the medical, nursing and allied health professions, and has introduced new health professions with specific roles within a new, team-based model of comprehensive health care.

- In medical education, the UK reforms span undergraduate, prevocational, vocational and continuing education, with the aim of providing a framework for faster, more flexible career development that can adapt to future changes in workforce need. While some reforms are controversial, most appear sensible and are supported by most observers.

- The Modernising Medical Careers process suffered implementation difficulties in 2007: the national, web-based application scheme for vocational training posts could not cope with such a large process, disrupting both the recruitment of an appropriate workforce for hospitals and the career progression of many recent UK medical graduates.

- The main problem appears to have been in management of change - too much was attempted too quickly on too large a scale — resulting in a backlash against any significant change.

- There may be lessons for Australia and New Zealand, which face similar challenges and are considering broadly similar changes.

MJA 2007; 187: 400-403

application of theory, development of skills and role modelling is largely up to the medical practitioners who supervise more senior medical students, recent graduates and specialty trainees. Clinical teachers may be more driven by aspirations for standards of individual care and maintaining professional integrity. The influence of health care management and politicians has increased only relatively recently, because the high cost of medical education is now more clearly visible amid large and generally overspent health care budgets, and there are more specific requirements of doctors. As is happening elsewhere, health care needs are changing because of the growing and ageing population, who will need increasingly expensive health care and have higher expectations of the quality of that care.

During the past decade, it was realised that the UK faced a substantial shortfall in the production of a locally trained workforce, and that it was risky to rely on immigration of doctors when global shortages of all categories of health care workers are predicted. The message from funders was that UK medical education would change to reflect current needs, and that the high costs 


\begin{tabular}{|c|c|c|}
\hline Level & Strategies & Responsibility \\
\hline Pre-medical school & $\begin{array}{l}\text { Widening participation and access to programs to broaden student } \\
\text { recruitment }\end{array}$ & $\begin{array}{l}\text { Medical schools } \\
\text { General Medical Council } \\
\text { Higher Education Funding Council }\end{array}$ \\
\hline Undergraduate & $\begin{array}{l}\text { Probable increased prescription of curriculum content } \\
\text { Possible national endpoint assessment process }\end{array}$ & General Medical Council \\
\hline Junior hospital training & $\begin{array}{l}\text { Integrated 2-year foundation program } \\
\text { Organisation through regional foundation schools }\end{array}$ & $\begin{array}{l}\text { Modernising Medical Careers } \\
\text { Strategic health authorities } \\
\text { Postgraduate deaneries }\end{array}$ \\
\hline Specialty training & $\begin{array}{l}\text { Clearer, nationally consistent specialty training programs } \\
\text { Organisation through regional specialty schools }\end{array}$ & $\begin{array}{l}\text { Modernising Medical Careers } \\
\text { Postgraduate Medical Education and } \\
\text { Training Board } \\
\text { Royal Colleges }\end{array}$ \\
\hline $\begin{array}{l}\text { Continuing professional } \\
\text { development }\end{array}$ & $\begin{array}{l}\text { Improved job planning for all medical staff } \\
\text { Annual appraisal of performance, jointly with university for academic } \\
\text { clinicians }^{7}\end{array}$ & $\begin{array}{l}\text { Local NHS trusts } \\
\text { Royal Colleges } \\
\text { Postgraduate deaneries }\end{array}$ \\
\hline
\end{tabular}

would be met largely from central funding. In implementing the reforms, funders have effectively taken more control over what the "product" is and does, more directly linking changing health care needs to the development of different work practices and workforce models. In addition to needing more medical graduates, funders want graduates who are able to fill new roles — including performing new skills, and filling new specialties and health professions.

However, reforming medical education is a long process, with several discrete stages that reflect levels of training, experience and value to society. The response in the UK has been across all levels (see Box 1), but has placed more emphasis on undergraduate and early career training. The number of students entering medical courses has almost doubled, to over 8000 by 2006, and so the number of graduates will almost double by around 2010-2011, ${ }^{4}$ providing the necessary pool of new trainees to replace the retiring senior consultants over the next 10 years or so. Early career training is changing through the efforts of the NHS group Modernising Medical Careers (MMC) $)^{5}$ — which aims to shorten total training times, provide clearer pathways and increase flexibility, ${ }^{6}$ as described in Box 2.

\section{Implementation of the reforms}

The reforms have been developed and implemented across all levels of medical education by several organisations, some of which are new. MMC is an NHS group that steers the development and implementation of reforms in postgraduate training, including the foundation programs and the entry to specialty training programs. ${ }^{5,8}$ The Postgraduate Medical Education and Training Board (PMETB) is an independent group responsible for the standards of specialty training curricula. ${ }^{9}$ The General Medical Council (GMC) has had to ensure that the expanded and new medical schools meet the required standards, outlined in Tomorrow's doctors. ${ }^{10}$ There has been uncertainty over the potential for overlap between the GMC and PMETB, and it is possible that the roles of both will change. ${ }^{11}$ Strategic health authorities (the regional health management structures) have restructured again, and the roles of the postgraduate deans appear also to be changing, as more responsibility is devolved from the NHS centrally to these authorities. Medical schools now work with regional foundation schools and a school for each postgraduate specialty, and are having to manage substantial expansion with an academic workforce that is not increasing, and is ageing. ${ }^{12}$ The medical education landscape is now increasingly complex.

The NHS is one of the largest health care organisations in the world. Although all of the above national organisations are striving to achieve the desired reforms, it is difficult to ensure that all those potentially involved understand the changes. The Royal Colleges were occupied obtaining approval for their curricula and do not appear to have been otherwise actively engaged in some of the reforms. The British Medical Association (BMA) was publicly supportive, despite disquiet among the membership. At the level of individual NHS trusts (the local health management structures), which would be responsible for providing training posts, supervisors, and interviewers for short-listed applicants, there appears to have been even less engagement.

The biggest challenge was the decision to implement the early career changes as soon as possible. The Foundation Programme was piloted in 2005 and then rolled out across the entire UK in 2006, arguably before all was ready. However, this change has been relatively successful, partly because there was always a sharp transition between medical school and early postgraduate training, and there were about equal numbers of applicants and posts. Encouraged by this success, the MMC team pushed ahead with plans to introduce the new process for selecting applicants for specialty training, commencing in August 2007, with no real piloting. Here the greatest challenge was the selection process, as

\section{Aims of Modernising Medical Careers ${ }^{5}$}

- Regulated access to foundation and specialty training posts

- Clearer criteria

- Clearer pathways

- More rapid progression

- Greater career flexibility

- Greater national consistency 
the training programs were ready, with PMETB-approved training curricula and regional training schools in place. The selection process was a key part of the reform, as it would address past criticisms by being based on merit alone, not the name of the medical school, "old boy" networks or favouritism by local panels. Further, applicants need apply only once, ranking choices, rather than applying to several different programs through different processes.

The choice of a web-based Medical Training Application System (MTAS), which just coped with the previous year's Foundation Programme applications, appeared to be an obvious solution for such a large process (about 22000 posts). However, the system failed to cope with the numbers of applicants (about 32 000), failed to provide meaningful data on which to rank applicants, and made openly available to anyone on the MMC website sensitive personal information about applicants. ${ }^{13}$ In the aftermath, the leadership of MMC and the BMA resigned, and the Secretary of State for Health faced a no-confidence motion in Westminster. ${ }^{14,15}$

There are important implications for medical education in the UK. Most observers would agree that some medical education reform is necessary, and even that the reforms within undergraduate medicine and early career progression were mostly reasonable and desirable. Had the MMC implementation been relatively trouble-free, then the reforms would most likely have proceeded without much difficulty, gaining acceptance and support. Instead, the failure of MTAS has allowed detractors - many of whom are simply opposed to some or all of the changes - to surface and appear to win. There is a substantial risk that necessary reforms may now not take place.

An important issue that may have long-term effects is the unexpected increase in the number of applicants. The NHS did not predict the "second wave" of increased applicants for UK specialty training - international medical graduates from the European Union. While recent immigration and licensing changes make it harder for international medical graduates from outside the European Economic Association (EEA) to work in the UK, ${ }^{16}$ it is easier for those from within this expanding organisation to come to the UK, because there are no migration barriers or language tests, and medical qualifications are automatically recognised. Hence, even before the expansion of UK undergraduate medical education has increased the pool of local applicants, the applicant pool is already larger than the available training posts. There are now realistic fears of unemployment and forced emigration of UK-trained medical graduates. If these gloomy predictions are accurate, there may be an even worse political crisis than that arising from the recent MTAS process.

\section{Lessons for Australia and New Zealand}

In looking back over events that went wrong, it is easy to be overly critical. On the other hand, almost certainly lessons may be learned from a case study of the UK reforms, particularly as most of the proposed reforms appear to be sensible and could, in principle, be applied in Australia and New Zealand. First, it is clear that workforce predictions are very difficult, as they rely on past data and current models to design the future. While it may not be possible to get this right, having a back-up plan seems a sound idea. For example, a back-up manual system should be designed into any large-scale web-based system, not developed late amid panic.

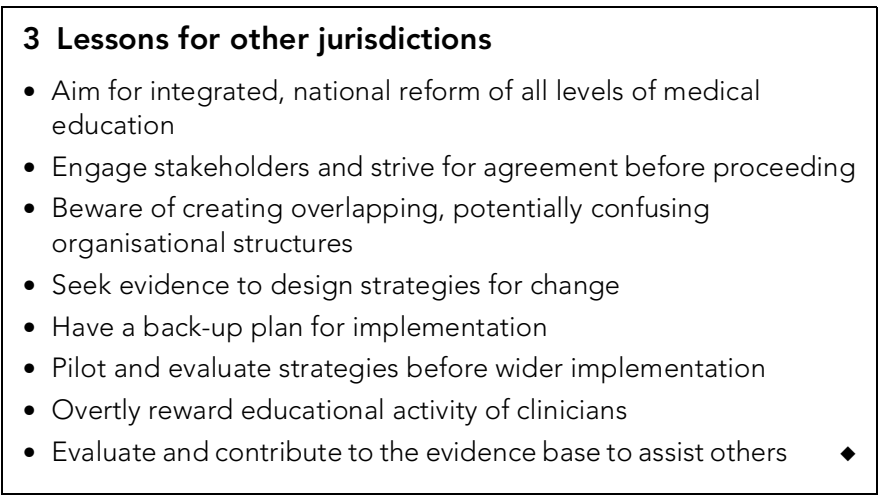

Second, although having a single, national health system is a potential advantage in implementing integrated, whole-of-system reform, the consensus is that too much was rushed though across the entire, large and complex system. The NHS is, in fact, a devolved structure, with 10 regional health structures in England, and separate regions in Wales, Northern Ireland and Scotland. It is therefore likely that reforms at each level of medical career progression could have been piloted in some regions before wider implementation, limiting the scale of negative consequences. Australia and New Zealand should consider using the different state and national jurisdictions to trial components of the reforms before wider application.

Third, it is difficult to effect reform at one level of medical education without considering the complexity of the whole education and training system. Dramatically increasing local medical graduate production without a plan to manage medical immigration now looks foolish. Undergraduate, early career and continuing medical education are closely interconnected. The Australian national junior doctor curriculum framework is a sound development, ${ }^{17}$ but, if early career training is to be reformed, it must be designed to cope with the expansion of undergraduate medical education.

Fourth, although there was widespread discussion within health management and medical education circles about the need for change and the chosen strategies, the level of engagement of the doctors who had to apply for, or implement, the system is unclear. Recent events suggest that most were not "ready" for the changes. A related issue is that of clarity of the complex organisational structures and their roles. While MMC was being developed, there was substantial debate about the roles and responsibilities of other professional bodies, such as the GMC, and the creation of new bodies, such as PMETB. Many participants appear confused about who is responsible for which part of medical education reform and implementation. Adherence to simple change-management theory and practice might have improved the acceptance of change and reduced the confusion.

Finally, while medical education reform will require a substantial investment of time and energy of thousands of clinicians, medical education does not often appear in the job plans and appraisal processes of most consultants and GPs, and is poorly rewarded. Medical education will need to be nurtured as a career pathway, probably alongside a more traditional medical career, and individuals on that pathway will need specific preparation and support. While it is early days, the new Academy of Medical Educators aims to improve career progress and support for those who choose to play a role in medical education in the $\mathrm{UK}^{18} \mathrm{~A}$ 


\section{MEDICAL EDUCATION}

similar initiative may be worth considering in Australia and New Zealand.

Potential lessons are summarised in Box 3. The message for other jurisdictions should be that, if medical education reform is necessary, it will be difficult unless done correctly, and the UK experience can provide constructive assistance.

\section{Conclusion}

Changes to medical education are inevitable and, indeed, are happening around us - often not as a single process or under the control of any single organisation, because of the complex surrounding organisational and political context. Resisting change is unlikely to succeed, and may well further fragment change and result in poor outcomes. The UK deserves applause for grappling with complex issues and imperfect data, and for designing comprehensive system reform that should produce a more flexible, "fitfor-purpose" medical workforce. The critical error in implementation was arguably in the management of change - moving too fast, too soon - almost certainly aggravated by the complexity of the system of medical education and the failure of a risky, webbased application system. Australia and New Zealand face similar medical education and workforce challenges, and should reflect on the UK experience before proceeding far with their own reforms.

\section{Author details}

Richard B Hays, MD, FRACGP, FACRRM, MRCGP, Head, and Chair of Medical Education ${ }^{1}$ and Chair of Medical Education ${ }^{2}$

1 School of Medicine, Keele University, Staffordshire, UK.

2 School of Medicine, Faculty of Health, Life and Molecular Sciences, James Cook University, Townsville, QLD.

Correspondence: r.b.hays@keele.ac.uk

This article is based on a keynote address to the MedEd 2007 Seamless Medical Education Conference held in Melbourne, Victoria, in April 2007.

\section{References}

1 National Health Service. About the NHS. http://www.nhs.uk /england/ aboutTheNHS/history/default.cmsx (accessed Aug 2007).

2 Fleming N. Calls for "NHS tax" to finance health care. Telegraph.co.uk (last updated 3 Jun 2007). http://www.telegraph.co.uk/news/ main.jhtml?xml=/news/2007/06/02/nhstax02.xml (accessed Aug 2007).
3 Hall J. Alliance Boots to put GPs in stores. Sunday Telegraph [London] (last updated 12 Jun 2007). http://www.telegraph.co.uk/money/ main.jhtml?xml=/money/2007/06/10/cnboots110.xml (accessed Jun 2007).

4 Higher Education Funding Council England. Increasing medical student numbers in England 2001. http://www.hefce.ac.uk/pubs/hefce/2001/01_ 31.htm (accessed Jun 2007).

5 Modernising Medical Careers. http://www.mmc.nhs.uk/pages/home (accessed Jun 2007).

6 Grant JR. Changing postgraduate medical education: a commentary from the United Kingdom. Med J Aust 2007; 186 (7 Suppl): S9-S13.

7 Follett B, Paulson-Ellis M. A review of appraisal, disciplinary and reporting arrangements for senior NHS and university staff with academic and clinical duties. A report to the Secretary of State for Education and Skills, September 2001. Department for Children, Schools and Families. http:// www.dfes.gov.uk/follettreview (accessed Jun 2007).

8 Hays RB. Foundation programme for newly qualified doctors. BMJ 2005: 331: 465-466.

9 Postgraduate Medical Education and Training Board. About us. http:// www.pmetb.org.uk/index.php?id=about (accessed May 2007).

10 General Medical Council. Tomorrow's doctors. London: GMC, 2003. http://www.gmc-uk.org/education/undergraduate/undergraduate_policy/tomorrows_doctors.asp (accessed Aug 2007).

11 National Health Service. Trust assurance and safety - the regulation of health professionals in the 21st century. London: NHS, 2007.

12 Margerison C, Morley H. Clinical academic staffing levels in UK medical and dental schools. A report by the Medical Schools Council and the Council of Heads and Deans of Dental Schools, London: Medical Schools Council, 2007

13 Macdonald V. Junior doctors' details exposed online. Channel4.com. http://www.channel4.com/news/articles/society/health/exclusive+junior+doctors+details+exposed+online/469137 (accessed Jun 2007).

14 Crockard A. Prof Alan Crockard's letter of resignation. Telegraph.co.uk (last updated 31 Mar 2007). http://www.telegraph.co.uk/news/ main.jhtml?xml=/news/2007/03/30/ndocletter130.xml (accessed Jun 2007).

15 Hawkes N. BMA chief quits after "damaging" defence of failed training system. The Times [London] 2007; 21 May. http://www.timesonline.co.uk/ tol/life_and_style/health/article1816620.ece (accessed Aug 2007).

16 Hays RB. Moving to the UK as a general practitioner: the process explained. Aust Fam Physician 2007; 36: 757-759.

17 Graham IS, Gleason AJ, Keogh GW, et al. Australian Curriculum Framework for Junior Doctors. Med J Aust 2007; 186 (7 Suppl): S14-S19.

18 The Academy of Medical Educators. FAQ sheet for the proposed Academy of Medical Educators. Association for the Study of Medical Education. http://www.asme.org.uk/academy/academy_faq.htm (accessed Jun 2007).

(Received 14 Jun 2007, accepted 12 Aug 2007)

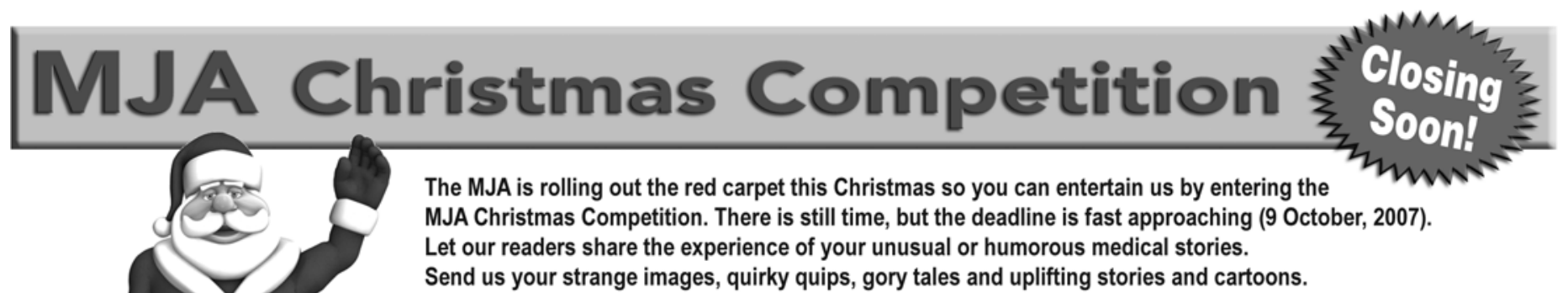

Send us your strange images, quirky quips, gory tales and uplifting stories and cartoons. You can win great prizes AND be published in the MJA, Australia's premier medical journal.

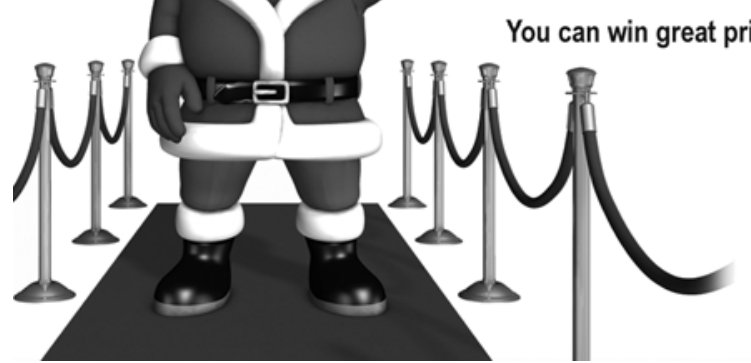

For full submission details visit: http://www.mja.com.au/public/information/instruc.html OR contact our Editorial Administrator: Phone 0295626666 • Email <medjaust@ampco.com.au> 
Reproduced with permission of the copyright owner. Further reproduction prohibited without permission. 